\title{
Review Article \\ Precursor Lesions for Sporadic Pancreatic Cancer: PanIN, IPMN, and MCN
}

\author{
M. Distler, ${ }^{1}$ D. Aust, ${ }^{2}$ J. Weitz, ${ }^{1}$ C. Pilarsky, ${ }^{1}$ and Robert Grützmann ${ }^{1}$ \\ ${ }^{1}$ Department of Visceral, Thoracic, and Vascular Surgery, University Hospital Carl Gustav Carus Dresden, TU Dresden, \\ Fetscher Street 74, 01307 Dresden, Germany \\ ${ }^{2}$ Institute for Pathology, University Hospital Carl Gustav Carus Dresden, TU Dresden, Fetscher Street 74, 01307 Dresden, Germany \\ Correspondence should be addressed to Robert Grützmann; robert.gruetzmann@uniklinikum-dresden.de
}

Received 18 November 2013; Revised 8 February 2014; Accepted 10 February 2014; Published 24 March 2014

Academic Editor: Sonshin Takao

Copyright (c) 2014 M. Distler et al. This is an open access article distributed under the Creative Commons Attribution License, which permits unrestricted use, distribution, and reproduction in any medium, provided the original work is properly cited.

Pancreatic cancer is still a dismal disease. The high mortality rate is mainly caused by the lack of highly sensitive and specific diagnostic tools, and most of the patients are diagnosed in an advanced and incurable stage. Knowledge about precursor lesions for pancreatic cancer has grown significantly over the last decade, and nowadays we know that mainly three lesions (PanIN, and IPMN, MCN) are responsible for the development of pancreatic cancer. The early detection of these lesions is still challenging but provides the chance to cure patients before they might get an invasive pancreatic carcinoma. This paper focuses on PanIN, IPMN, and $\mathrm{MCN}$ lesions and reviews the current level of knowledge and clinical measures.

\section{Introduction}

Pancreatic cancer is the fourth leading cause of cancer death in the USA [1]. The high mortality rate is mainly caused by the lack of highly sensitive and specific tools to detect the disease in an early stage, and therefore most of the patients are diagnosed in advanced tumor stages. Currently, surgical resection is the only curative treatment option. However, only a small number of patients (30-40\%) present with a resectable tumor at the time of diagnosis. The overall five-year survival after pancreatic head resection for cancer has been reported to range between 10 and $25 \%[2,3]$. The five-year survival rate can be significantly improved for patients with pancreatic cancer when surgery is possible and patients additionally receive adjuvant therapy $[4,5]$. However, there are patients that relapse shortly after the surgery and, therefore, have only a limited life span even after complete resection of the tumor.

Current knowledge about pancreatic carcinogenesis postulates-analogous to other carcinomas-a stepwise progression from intraepithelial neoplasia to invasive cancer $[6,7]$. Studies of resected pancreata from patients with a family history of pancreatic cancer or from patients with ductal adenocarcinoma of the pancreas (PDAC) demonstrated that many patients have multifocal, microscopic pancreatic intraepithelial neoplasms (PanINs) surrounding the tumor and in the remainder of the pancreas [8-11]. Furthermore, cystic lesions of the pancreas like intraductal papillary mucinous neoplasms (IPMNs) or mucinous cystic neoplasms (MCNs) are well known as precursor lesions for pancreatic cancer (Figure 1) [12-15]. Early detection and treatment of the abovementioned precursor lesions could probably save patients from advancing to invasive pancreatic cancer. In this review, a summary of the most important precursor lesions for pancreatic cancer, that is, PanIN, IPMN, and MCN, is given.

\section{Pancreatic Intraepithelial Neoplasia (PanIN)}

The most important and well-known precursor of a PDAC is pancreatic intraepithelial neoplasia (PanIN). For several decades, this noninvasive ductal lesion was described using multiple terminologies. Hruban et al. first presented the nowadays generally accepted "PanIN scheme" to classify these lesions in 2001 (Figure 2) [16, 17]. 


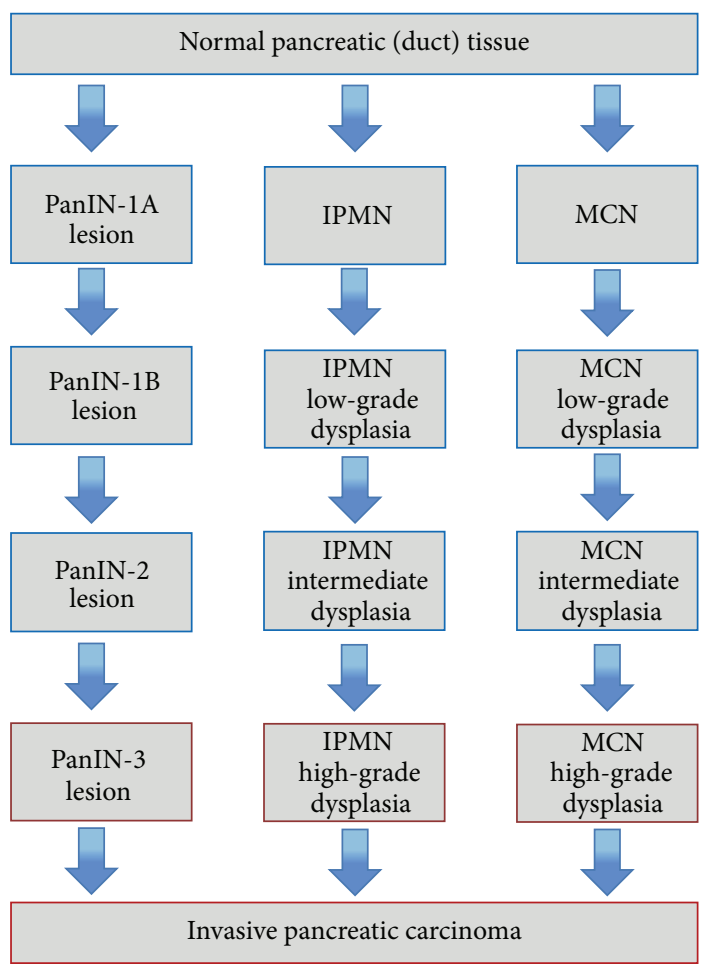

FIGURE 1: Model of three distinct morphological pathways to invasive pancreatic carcinoma.

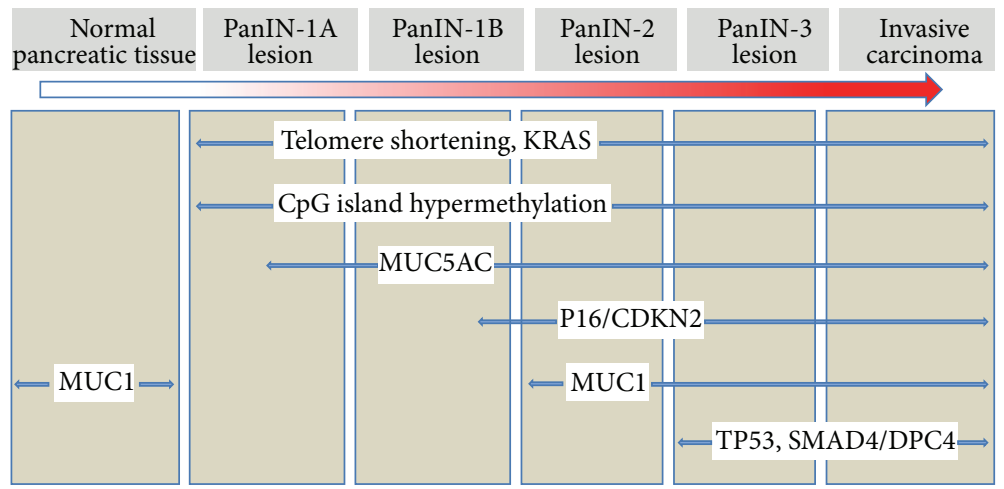

Figure 2: Compendium of molecular changes during the PanIN-progression model. Adapted from [6, 18].

2.1. Histology. A PanIN is a microscopic (usually $<5 \mathrm{~mm}$ ) flat or papillary lesion arising in the small intralobular pancreatic ducts [17]. These lesions are characteristically asymptomatic. PanINs are composed of columnar to cuboidal cells with varying amounts of mucin and varying degrees of cytological and architectural atypia [15]. They are classified into three grades: PanIN-1A (flat) and PanIN-1B (papillary) are low-grade lesions with minimal cytological and architectural atypia (Figure 3). PanIN-2 lesions (intermediate-grade PanIN) show mild to moderate cytological and architectural atypia (e.g., nuclear pleomorphism, nuclear crowding, and nuclear hyperchromasia) with frequent papillae (Figure 4) $[6,15]$. High-grade PanINs (PanIN-3) are characterized by severe cytological and architectural atypia. PanIN-3 is also referred to as "carcinoma in situ." All PanINs are noninvasive lesions that do not trespass the basement membrane [16, 17].
PanIN-3 lesions usually have a papillary morphology but can also present with a flat or cribriform pattern (Figure 4). In addition, there are some rare variants of PanINs (e.g., intestinal type, foam gland type, and oncocytic type) that do not seem to have any specific clinical significance [15].

Formal pancreatic carcinogenesis is thought to progress from low-grade to high-grade PanIN and then to invasive cancer; this histological progression is paralleled by the accumulation of genetic changes (Figure 2).

2.2. Immunohistochemical Characteristics. The immunohistochemical characteristics of PanINs vary with the grade of dysplasia. In particular, the apomucins MUC1, MUC2, and MUC5AC are frequently overexpressed in epithelial cancers of the gastrointestinal tract $[14,19]$. MUC1 is responsible for the surveillance of lumen formation and is typically expressed 


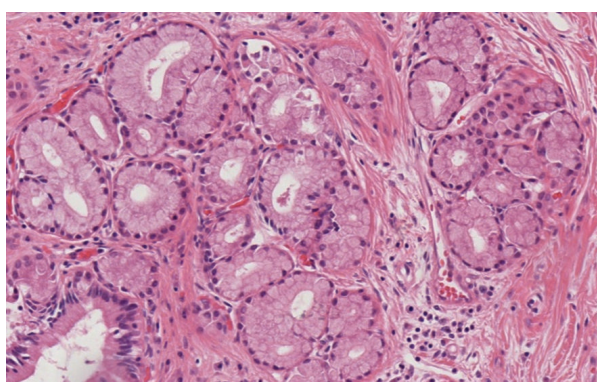

(a)

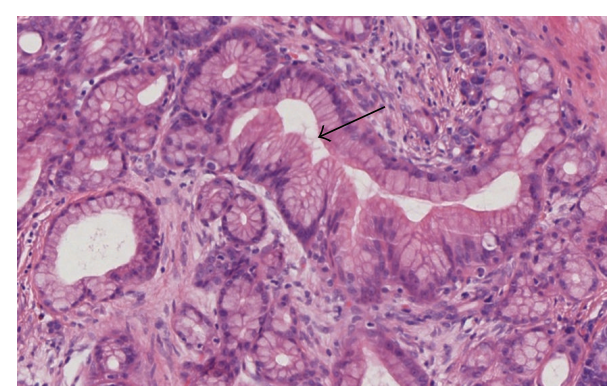

(b)

Figure 3: (a) PanIN 1A lesion with flat epithelium, basal nuclei, and abundant supranuclear mucin. (b) PanIN 1A and 1B (arrow) lesion with papillary architecture and slight nuclear atypia $(\mathrm{H} \& \mathrm{E} \times 20)$.

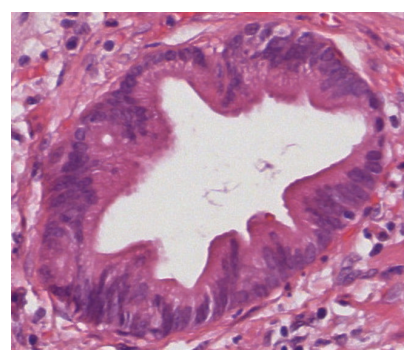

(a)

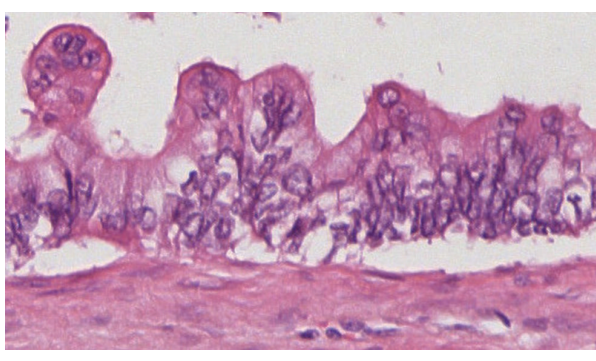

(b)

FIGURE 4: (a) PanIN-2 lesion with moderate cytological atypia, retained nuclear polarity, and partially papillary architecture (H\&E, 20x); (b) PanIN-3 lesion with severe cytological atypia, lost nuclear polarity, and papillary architecture (H\&E, 40x).

by the pancreatic ducts and centroacinar cells. Furthermore, MUC1 is almost exclusively expressed in the higher-graded lesions (PanIN-2/PanIN-3) and often linked with an invasive PDAC [18, 20]. The intestinal mucin marker MUC2 and the intestinal differentiation marker CDX-2 are negative in common-type PanIN and PDAC. However, MUC2 and CDX2 expression is seen in IPMNs with intestinal differentiation and therefore can be used for differentiation between PanINs and intestinal IPMNs $[14,19,21]$. In contrast to MUC1, MUC5AC is not expressed by the normal pancreatic ducts but, similar to MUC1, in the majority of invasive ductal carcinomas and moreover already in the early PanIN lesions $[6,18,20,22,23]$. Furthermore, the membrane-associated mucins MUC3 and MUC4 show a progressive increase in PanIN lesions of increasing dysplasia and are also highly expressed in ductal adenocarcinoma $[20,24,25]$.

2.3. Genetic and Epigenetic Changes. As mentioned above, PanINs are part of the multistep tumor progression model in pancreatic cancer. Early genetic alterations include telomerase shortening, V-Ki-ras2 Kirsten rat sarcoma viral oncogene homolog (KRAS) activation, and inactivation of tumor suppressor genes cyclin-dependent kinase inhibitor p16 (p16)/cyclin-dependent kinase inhibitor 2A (CDKN2A) [17]. KRAS mutations are one of the earliest genetic abnormalities in the progression model for pancreatic cancer [26]. The most common activating point mutations are located in codons 12 and 13 of exon 2 of the KRAS gene (in over $90 \%$ of PDACs) $[6,27,28]$. Early KRAS mutation is thought to be the driver for the formation of pancreatic cancer [29].

Telomere shortening is another early event in the progression model of pancreatic cancer. Telomeres are structures at the end of the chromosomes with a protective effect. They prevent fusion between the ends of the chromosomes. Telomeres shorten with the age of the cell and the number of cell divisions. Shortened telomeres lead to an abnormal fusion of chromosomes with chromosome instability, promoting neoplastic progression in the cells $[6,30]$.

In addition to activating KRAS mutations, leading to increased proliferation, and telomere shortening, leading to chromosomal instability, the inactivation of three tumor suppressor genes (p16/CDKN2A, tumor protein 53 (TP53), and SMAD family member 4 (SMAD4/DPC4)) is relevant for the formation of pancreatic cancer. While the inactivation of p16/CDKN2A is already detectable in the early PanIN stages, the inactivation of TP53 and SMAD4/DPC4 is associated with later alterations in the tumor progression model [17]. The p16/CDKN2A gene is located on the short arm of chromosome 9, and almost all pancreatic carcinomas present a loss of the p16/CDKN2A function [31]. Inactivation of p16 leads to an inadequate progression through the G1 phase of the cell cycle.

The TP53 tumor suppressor gene encodes for the p53 protein that is involved in the regulation of the cell cycle, maintenance of the G2/M arrest, and the induction of 
apoptosis. Loss of p53 causes deregulation in cell death and cell division $[18,32]$.

The gene DPC4 (located on chromosome 18q) encodes for the SMAD4 protein that plays an important role in signaling through the transforming growth factor type $\beta$ (TGF- $\beta$ ) pathway. SMAD4 has a growth-controlling effect by regulating the expression of specific genes $[33,34]$. Therefore, loss of SMAD4 leads to a decreased growth inhibition and thereby supports the growth of cancer cells.

Epigenetic changes predominantly occur through methylation of CpG islands, which are located in the promoter regions of genes leading to gene silencing [35]. Numerous studies have demonstrated hypermethylation of several genes in patients with pancreatic cancer $[36,37]$. A microarray analysis by Sato et al. showed that aberrant CpG island hypermethylation begins in early stages of PanINs, and its prevalence progressively increases during neoplastic progression [38]. Furthermore, the detection of aberrantly methylated genes by methylation-specific PCR in the pancreatic juice might be an interesting diagnostic tool for the future [39].

2.4. Clinical Relevance of PanIN. As mentioned above, PanIN lesions are precursor lesions in the stepwise progression from intraepithelial to invasive pancreatic neoplasia. This morphological progression is paralleled by an accumulation of genetic changes in which activating KRAS mutations are thought to be the driving force (Figure 2). Early detection of PanINs would present an opportunity to cure patients before they develop invasive pancreatic cancer, but unfortunately PanINs are not yet detectable by cross-sectional imaging or endoscopic ultrasound (EUS). Molecular markers in the pancreatic juice may help to solve this dilemma. The most appropriate approach to the pancreatic resection margin when it harbors a PanIN lesion (detected by intraoperative frozen section) is, however, not clear. In particular, no consensus has been achieved on how to handle PanIN-3 lesions in the resection margin [40]. We would recommend an additional resection in cases with PanIN-3 lesions (in the resection margin), whereas an additional resection in PanIN1 and -2 lesions might not be necessary.

\section{Intraductal Papillary Mucinous Neoplasm (IPMN)}

IPMNs belong to the heterogeneous group of cystic pancreatic lesions with increasing incidence in recent years [41-43]. These cystic lesions were initially reported in the 1990s, and the term IPMN was established in the 2000 classification of the WHO [44]. IPMNs are tumors of the duct epithelium. Papillary epithelial proliferation and mucin production lead to cystic dilatation of involved ducts [43]. IPMNs have been proven to be invasive carcinoma precursors, and thus progression models from noninvasive intraductal tumors via borderline lesions to invasive carcinoma have been developed (Figure 1) [45-47].

3.1. Histology and Immunohistochemistry. Morphologically, IPMNs are subdivided into the main (MD-IPMN) and branch duct types (BD-IPMN) according to their site of
TABLE 1: Subtype classification of IPMN by immunohistochemical analysis and arising invasive carcinoma [48-50].

\begin{tabular}{|c|c|c|}
\hline IPMN (subtype) & Expression profile & Invasive carcinoma \\
\hline $\begin{array}{l}\text { Intestinal } \\
(\mathrm{MD}-\mathrm{IPMN})\end{array}$ & $\begin{array}{l}\mathrm{MUC5AC}^{+}, \mathrm{MUC2}^{+} \text {, } \\
\mathrm{CDX}^{+}{ }^{+} \\
\left(\mathrm{MUCl}^{-}, \mathrm{MUC6}^{-}\right)\end{array}$ & $\begin{array}{l}\text { Colloidal } \\
\text { carcinoma }\end{array}$ \\
\hline $\begin{array}{l}\text { Pancreatobiliary } \\
(\mathrm{MD}-\mathrm{IPMN})\end{array}$ & $\begin{array}{l}\text { MUC5AC } \\
\left(\mathrm{MUC2}^{-}, \mathrm{MUCl}^{+}\right. \\
\left.\mathrm{MUC6}^{+/-}\right)\end{array}$ & $\begin{array}{l}\text { Tubular (ductal) } \\
\text { carcinoma }\end{array}$ \\
\hline $\begin{array}{l}\text { Gastric } \\
(\mathrm{BD}-\mathrm{IPMN})\end{array}$ & $\begin{array}{l}\text { MUC5AC }{ }^{+},\left(\mathrm{MUC6}^{+}\right) \\
\left(\mathrm{MUC1}^{-}, \mathrm{MUC2}^{-}\right)\end{array}$ & $\begin{array}{l}\text { Tubular (ductal) } \\
\text { carcinoma }\end{array}$ \\
\hline $\begin{array}{l}\text { Oncocytic } \\
(\mathrm{MD}-\mathrm{IPMN})\end{array}$ & $\begin{array}{l}\text { MUC5AC }{ }^{+}, \mathbf{M U C 6}^{+} \\
\left(\mathrm{MUC2}^{+/-}\right)\left(\mathrm{MUCl}^{+/-}\right)\end{array}$ & $\begin{array}{l}\text { Oncocytic } \\
\text { carcinoma }\end{array}$ \\
\hline
\end{tabular}

origin. When the main and branch ducts are both involved, the terms "mixed duct type" and "combined duct type" are used $[51,52]$. Due to the papillary epithelial proliferation and mucin production, MD-IPMNs typically show a dilatation of the main pancreatic duct $>6 \mathrm{~mm}$. BD-IPMNs show no dilatation of the main pancreatic duct but a communication of the cystic lesion with the main duct, typically well definable by MRI/MRCP imaging. Some IPMNs might be multifocal and therefore even after partial pancreatic resection there is a risk of progression of a synchronous cystic lesion $[53,54]$. Depending on their degree of dysplasia and the presence or absence of an associated invasive carcinoma, IPMNs are subclassified by the WHO into lowgrade dysplasia, intermediate-grade dysplasia, high-grade dysplasia, and IPMN with associated invasive carcinoma [55]. Approximately, one-third of patients with IPMN are associated with invasive carcinoma $[12,14,51,56]$. On the basis of their histological and immunohistochemical characteristics, intestinal, pancreatobiliary, oncocytic, and gastric subtypes of IPMN are distinguishable [14, 57]. Differential diagnosis of histopathological subtypes is accomplished by histomorphological and immunohistochemical analysis of MUC expression (MUC1, MUC2, MUC5AC, and MUC6) and the intestinal marker CDX-2 (Table 1) [19, 57, 58].

Intestinal-type IPMN is characterized by tall columnar cells with elongated nuclei and amphophilic cytoplasm (similar to villous adenoma of the colorectum). The lesions frequently exhibit moderate or severe dysplasia [15]. These villous papillary neoplasms typically show an expression of MUC2, MUC5AC, and CDX-2 (Figure 5) (Table 1). A recent article by Kitazono et al. also demonstrated MUC4 expression in IPMN and especially in intestinal-type IPMN [59].

In contrast, the pancreatobiliary subtype of IPMN is characterized by branched papillae with high-grade intraepithelial neoplasms. The pancreatobiliary subtype is usually associated with an invasive component/IPMN-associated carcinoma. Immunohistochemical staining shows expression of MUC1 and MUC5AC (Figure 5) (Table 1) [60]. The third and rare subtype of MD-IPMN is the oncocytic type. This subtype mainly presents with oncocytic cells with a complex branched papillary structure and an eosinophilic cytoplasm (with intracytoplasmic lumina) mixed with goblet cells and mucin-containing cells [15]. Most of these cells show highgrade cellular atypia and carcinoma in situ modifications 


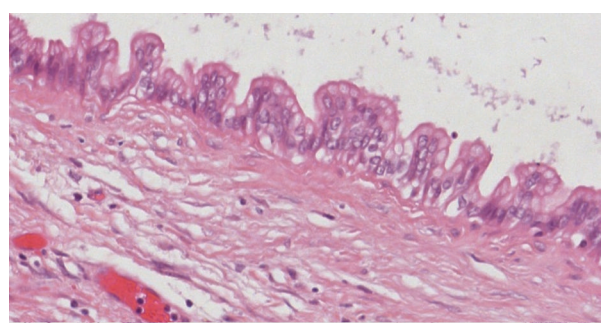

(a)

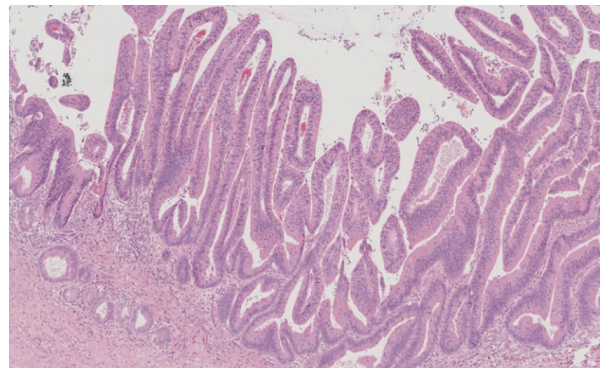

(c)

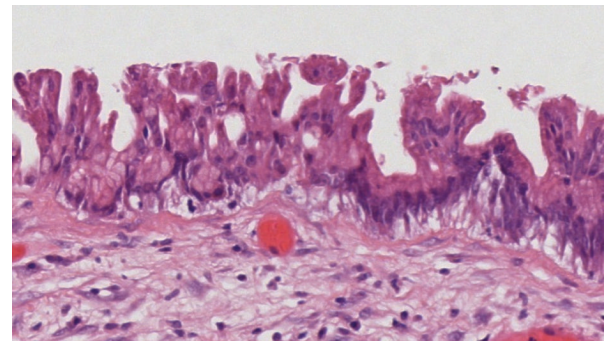

(e)

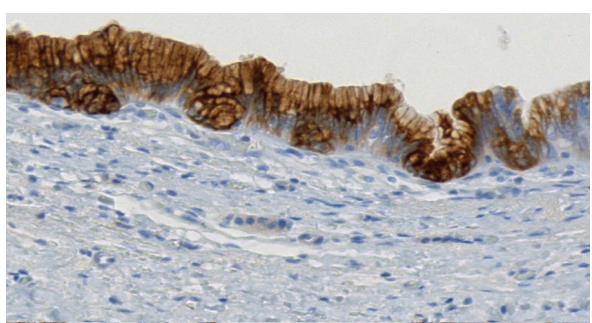

(b)

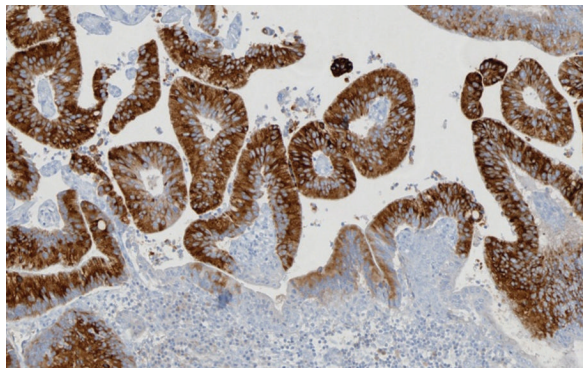

(d)

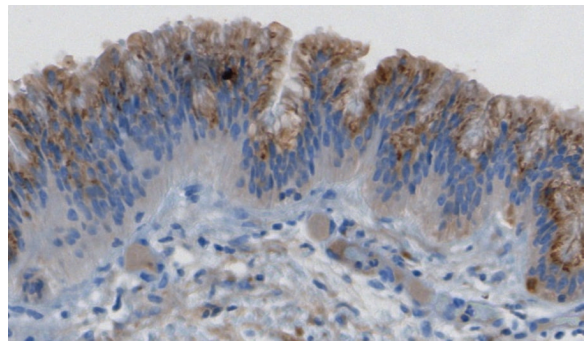

(f)

FIGURE 5: (a) and (b) IPMN gastric foveolar (branch duct) subtype with low-grade dysplasia, partially flat, partially papillary architecture, and basally oriented nuclei ((a); H\&E 20x, (b); MUC5AC 20x); (c) and (d) IPMN intestinal subtype with low/intermediate dysplasia, long, finger-like papillae, and elongated nuclei ((c); H\&E 4x, (b); MUC2 10x); (e) and (f) IPMN pancreatobiliary subtype with high-grade dysplasia, lost nuclear orientation, and complex papillae formation ((e); H\&E 20x, (f); MUC1 20x).

and convert into the infrequent oncocytic carcinoma when they become invasive. The oncocytic subtype is immunohistochemically characterized by a diffuse positivity for MUC5AC, MUC6, and a focal positivity for MUC1 or MUC 2 (Table 1). The gastric subtype, mainly found in BD-IPMN, is characterized by a foveolar glandular epithelium (similar to gastric foveolar cells) with formation of papillae. The cells present with oval-shaped nuclei with mild atypia and a slightly eosinophilic cytoplasm. Mitoses are rare, and most of the gastric-type lesions are low-grade lesions. Gastric-type IPMNs express MUC5AC and sometimes MUC6 (Table 1) $[48,49,61]$.

While intestinal, pancreatobiliary, and oncocytic subtypes primarily originate in the main duct, the gastric subtype is typically derived from branch ducts. When IPMNs become invasive, two distinct types of invasive carcinomas typically develop, that is, tubular and colloid (mucinous noncystic) carcinomas (Table 1) [14, 45, 62]. While colloid carcinomas (characterized by abundant extracellular pools of mucin with floating neoplastic epithelium) usually arise from intestinal-type IPMNs, thetubular adenocarcinoma mainly arising from pancreatobiliary-type IPMN (invasive IPMN) and PDAC are morphologically similar, but they may not be the same. For instance, tubular-type invasive IPMN may harbor GNAS mutations. The distinction of these two tumor types has prognostic relevance because patients with colloid carcinomas have a better five-year survival rate than patients with tubular carcinomas $[14,48,63,64]$. Other factors determining the prognosis of patients with IPMN are the presence of an invasive carcinoma, the lymph node ratio, and the histopathological subtype $[56,65,66]$.

3.2. Molecular Pathology and Genetic Changes. Studies have identified a wide variety of genetic changes in IPMNs and some of them are similar to the findings in PDAC including KRAS, p16/CDKN2A, SMAD4, and TP53 genes $[55,67]$. Other mutations, such as phosphatidylinositol-4,5bisphosphate 3-kinase (PIK3CA) and v-Raf murine sarcoma viral oncogene homolog $\mathrm{B} 1$ gene (BRAF) mutations, are found in a small fraction of IPMNs $[68,69]$. Recent studies by $\mathrm{Wu}$ et al. and Furukawa et al. added important information about the molecular anomalies of IPMN [70, 71]. They found that $>96 \%$ of IPMNs have either a GNAS complex locus (GNAS) or a KRAS mutation and more than half of them 
TABLE 2: Core characteristics of cystic lesions of the pancreas (adapted from [47]).

\begin{tabular}{|c|c|c|c|c|c|}
\hline & IPMN & SCN & $\mathrm{MCN}$ & SPN & Pseudocysts \\
\hline Mean age (years) & $60-70$ & 70 & $40-50$ & 30 & $30-50$ \\
\hline Sex & $\begin{array}{l}60-70 \% \\
\text { male }\end{array}$ & $\begin{array}{l}90 \% \\
\text { female }\end{array}$ & $\begin{array}{l}>95 \% \\
\text { female }\end{array}$ & $\begin{array}{l}90 \% \\
\text { female }\end{array}$ & $\begin{array}{l}70-80 \% \\
\text { male }\end{array}$ \\
\hline $\begin{array}{l}\text { Localization } \\
\text { (average) }\end{array}$ & Pancreatic head & Pancreatic tail & Pancreatic body and tail & $\begin{array}{l}\text { Pancreatic body and } \\
\text { tail }\end{array}$ & Pancreas ubiquitary \\
\hline Imaging and MPD & $\begin{array}{l}\text { Segmental or diffuse } \\
\text { enlargement of the } \\
\text { MPD and obligatory } \\
\text { communication to the } \\
\text { MPD }\end{array}$ & $\begin{array}{l}\text { Microcystic lesion } \\
\text { with central scar and } \\
\text { calcification (or } \\
\text { macrocystic lesion } \\
\text { without central scar } \\
\text { possible); no } \\
\text { connection to the } \\
\text { MPD }\end{array}$ & $\begin{array}{l}\text { Macrocystic lesion with } \\
\text { septation and calcification } \\
\text { of the wall; no connection } \\
\text { to the MPD }\end{array}$ & $\begin{array}{l}\text { Mixed solid cystic } \\
\text { lesion; no connection } \\
\text { to the MPD }\end{array}$ & $\begin{array}{l}\text { Macrocystic lesion } \\
\text { without septation; } \\
\text { connection to the } \\
\text { MPD and probably } \\
\text { signs of pancreatitis; } \\
\text { enlargement of MPD } \\
\text { possible }\end{array}$ \\
\hline CEA in cyst & High & Low & High & Low & Low \\
\hline Mucin production & Yes & No & Yes & No & No \\
\hline Amylase in cyst & High & Low & Low & Low & High \\
\hline
\end{tabular}

MPD: main pancreatic duct; CEA: carcinoembryonic antigen; IPMN: intraductal papillary mucinous neoplasm; SCN: serous cystic neoplasm; MCN: mucinous cystic neoplasm; SPN: solid pseudopapillary neoplasm.

have both mutations. The results of these studies indicate that GNAS mutations are common and specific for IPMN, and activation of G-protein signaling appears to play a pivotal role in IPMN. Although these mutations were found in all IPMN subtypes, GNAS mutations were more prevalent in the intestinal subtype, whereas KRAS mutations were more prevalent in the pancreatobiliary subtype [70-72]. Only a little is known about the characteristics of the oncocytic subtype of IPMN. KRAS mutations and TP53 overexpression are less frequently identified in oncocytic-type IPMN than in pancreatobiliary-type IPMN (17\% and $11 \%$ versus $58 \%$ and $58 \%$, resp.). However, the less frequent TP53 overexpression in the oncocytic subtype, associated with significantly lower rates of invasion and nodal involvement, correlates with a better outcome compared to pancreatobiliary-type IPMN $[14,73]$.

Current studies have evaluated the identification of molecular markers in the pancreatic juice. Siddiqui et al. demonstrated that the presence of GNAS in combination with KRAS mutations in pancreatic cystic fluid obtained by EUS-FNA improves the sensitivity for diagnosis of IPMN (accuracy $80 \%$ ) compared to CEA or KRAS alone [74]. Another study by Kanda et al. identified GNAS mutations in $64.1 \%$ of the patients in a screening population with IPMN [75]. The same group detected TP53 mutations in the pancreatic juice in $9.1 \%$ of intermediate-grade IPMNs, $17.8 \%$ of PanIN2 lesions, $38.1 \%$ of high-grade IPMNs, $47.6 \%$ of PanIN-3 lesions, and $75 \%$ of invasive pancreatic adenocarcinomas. Interestingly, no TP53 mutations were found in PanIN-1 lesions or low-grade IPMNs [76]. Although GNAS, KRAS, and TP53 mutations are helpful in identifying patients with IPMN, they occur early in the development of IPMNs and cannot be used to identify those individuals with high-grade dysplasia or invasive disease. Das et al. recently published seminal results regarding the detection of high-risk IPMN lesions. By analyzing the cyst fluid of IPMNs, they found that the monoclonal antibody Das-1 has $89 \%$ sensitivity and $100 \%$ specificity to detect high-risk/malignant IPMNs [77].

Moreover, recent reports demonstrated a level of hypermethylation in IPMN (e.g., p16/CDKN2A, cyclin-dependent kinase inhibitor 1C (CDKN1C), SRY- (sex determining region Y-) box 17 (SOX17)). An increasing number of hypermethylated loci are associated with an increasing grade of dysplasia [78].

3.3. Clinical Relevance of IPMN. In summary, IPMNs are premalignant cystic lesions usually arising from intestinal type IPMN, the tubular adenocarcinoma can be detected and treated before the onset of malignancy. A current challenge is the differentiation of cystic lesions (serous cystic neoplasm (SCN), mucinous cystic neoplasm (MCN), solid pseudopapillary neoplasm (SPN), and pseudocysts) and especially IPMN preoperatively. These cystic lesions appear different in clinical and radiologic diagnostic [47]. Table 2 summarizes the core characteristics of the different cystic pancreatic lesions. In particular, diagnostic classification of the IPMN subtypes (e.g., by cystic fluid) is important for individualized patient treatment.

Generally, resection of all MD-IPMNs (and mixed ducttype IPMN) and of BD-IPMNs with "worrisome features" is indicated. The recently published revised international consensus guidelines discuss this topic in detail [50].

Better markers are required to accurately identify patients who would benefit from surgical resection or could be placed under surveillance. The examination of pancreatic juice/cystic fluid seems to be a promising diagnostic option. Recently, Hara et al. showed that pancreatic juice cytology with MUC stain is highly reliable for the identification of the histological subtypes of IPMN [79]. Other authors reported about the identification of high-risk/malignant lesions by examination of the cyst fluid of IPMNs either by analyzing the MUC expression and cyst fluid cytokine levels (e.g., 


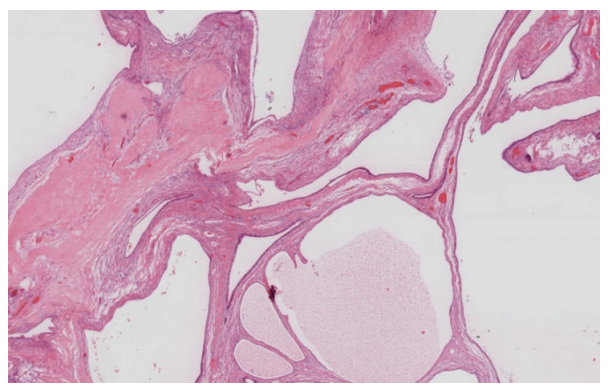

(a)

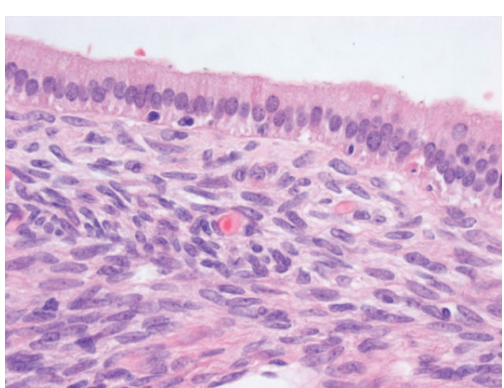

(b)

FIGURE 6: (a) Overview of a multicystic MCN (H\&E 2x) with cuboidal to columnar epithelial lining, mild dysplasia, and underlying ovarian type stroma. (b) High power view of MCN with columnar epithelial lining and underlying ovarian type stroma (H\&E 40x).

interleukin-1 beta) or by recognition of atypical cell components [80-83].

\section{Mucinous Cystic Neoplasm (MCN)}

MCNs of the pancreas are the most infrequent precursor lesions of pancreatic cancer. The accurate prevalence of MCN is difficult to assess; a recent publication by Valsangkar et al. reported about $23 \%$ of $\mathrm{MCN}$ in patients with resected cystic tumors of the pancreas [84]. MCNs mainly occur in women and are typically located in the pancreatic body and tail $[42,60,85,86]$. These cystic lesions are almost solitary and the vast majority of MCNs are asymptomatic and found incidentally [15]. On imaging, the cysts appear septated and may contain calcifications. Like IPMNs, MCNs as mucinous pancreatic lesions have a high CEA and mucinous cytology in the cyst fluid $[87,88]$. In contrast to IPMNs, MCNs usually present no obvious connection to the main pancreatic duct and no dilatation of the main pancreatic duct is typically detectable [12]. The prognosis for patients with noninvasive MCN is very favorable (five-year survival almost 100\%), and also for patients who undergo resection for an invasive $\mathrm{MCN}$ the five-year survival rate is nearly up to $60 \%$ [86].

4.1. Histology and Pathogenesis. MCNs are cystic lesions that can grow very large. They present with a plain surface and a fibrous pseudocapsule with variable thickness and often with calcifications. The presence of mural nodules on the inside of the capsule correlates with malignancy $[15,89]$. Microscopically, the epithelial lining of an MCN consists of columnar cells with a varying degree of dysplasia (Figure 6). On the basis of the degree of dysplasia (atypia), noninvasive MCNs are classified into low-grade dysplasia, moderate dysplasia, and high-grade dysplasia. About one-third of MCNs become invasive, and when they do, they usually form ductal adenocarcinomas [90].

Furthermore, one of the diagnostic clues of MCNs is the presence of an ovarian-like stroma underlying the neoplastic epithelium. The stroma expresses progesterone and estrogen receptors and can even undergo luteinization akin to the actual ovarian stroma $[12,89]$. The epithelial cells of MCNs show immunoreactivity for epithelial markers including EMA, CEA, and cytokeratins 7, 8/18, and 19 and for the mucin markers MUC5AC and MUC2. MUC1 is usually expressed in high-grade lesions and invasive carcinomas. The ovarian-like stroma is positive for vimentin and smooth-muscle actin in addition to the progesterone receptor and estrogen receptor $[15,89]$.

4.2. Molecular Pathology. The molecular changes underlying MCN formation and progression are not entirely clear. KRAS mutations have been detected in MCNs with lowgrade dysplasia and with increased frequency in advanced cases, while mutations of TP53, p16, and SMAD4/DPC4 have been mainly observed in high-grade dysplasia and invasive carcinomas $[12,23,91,92]$. A recent exome sequencing analysis by $\mathrm{Wu}$ et al. showed that MCNs contain an average of $16 \pm 7.6$ somatic mutations (cf. with $27 \pm 12$ for IPMNs) and are characterized by KRAS, TP53, and RING-type zinc finger protein 43 (RNF43) mutations [93]. Interestingly, in this analysis, MCN harbored no mutations of GNAS and therefore GNAS may be a useful marker for the differentiation between IPMN and MCN.

4.3. Clinical Relevance of MCN. Although MCNs harbor a low risk of malignancy (prevalence of invasive carcinoma about $13 \%$ ), surgery is indicated for any patient. Because, in particular, MCNs mainly occur in young patients and are mostly located in the body and tail of the pancreas, resection is the most appropriate and reliable treatment $[42,50]$.

Only frail and elderly patients for whom surgery is a higher risk should be placed under surveillance $[15,50]$.

\section{Conclusion}

There is still a lot to be learned about the biology of the three different precursor lesions of pancreatic cancer (PanIN, IPMN, and MCN). Early detection of these lesions would create an opportunity to prevent patients from developing invasive pancreatic cancer. However, clinical detection of these lesions is still challenging, even with modern highresolution imaging methods. Currently, PanIN lesions (especially $<5 \mathrm{~mm}$ ) are not detectable using available imaging methods. Moreover, diagnostic differentiation of the different cystic pancreatic lesions (i.e., IPMN from MCN or SCN and $\mathrm{SPN}$ ) is often complicated. 
From this comes the need for reliable biomarkers to detect and differentiate precursor lesions for pancreatic cancer. Analyzing genetic alterations in pancreatic juice/cystic fluid may be a diagnostic option for the future, as preliminary studies have already demonstrated. Prospective studies to validate these markers are needed to put them into clinical practice.

$\begin{array}{ll}\text { Abbreviations } \\ \text { PanIN: } & \text { Pancreatic intraepithelial neoplasia } \\ \text { PDAC: } & \text { Pancreatic ductal adenocarcinoma } \\ \text { IPMN: } & \text { Intraductal papillary mucinous neoplasm } \\ \text { MCN: } & \text { Mucinous cystic neoplasm } \\ \text { MD-IPMN: } & \text { Main duct intraductal papillary mucinous } \\ & \text { neoplasm } \\ \text { BD-IPMN: } & \text { Branch duct intraductal papillary } \\ & \text { mucinous neoplasm } \\ \text { SPN: } & \text { Solid pseudopapillary neoplasm } \\ \text { SCN: } & \text { Serous cystic neoplasm. }\end{array}$

\section{Conflict of Interests}

The authors declare that there is no conflict of interests regarding the publication of this paper.

\section{Acknowledgment}

The authors acknowledge the service of "Proof-ReadingService.com" (Hertfordshire, UK) for English language editing of the paper.

\section{References}

[1] R. Siegel, D. Naishadham, and A. Jemal, "Cancer statistics, 2012," CA Cancer Journal for Clinicians, vol. 62, no. 1, pp. 10-29, 2012.

[2] J. M. Winter, J. L. Cameron, K. A. Campbell et al., "1423 Pancreaticoduodenectomies for pancreatic cancer: a singleinstitution experience," Journal of Gastrointestinal Surgery, vol. 10, no. 9, pp. 1199-1210, 2006.

[3] M. Distler, F. Rückert, M. Hunger et al., "Evaluation of survival in patients after pancreatic head resection for ductal adenocarcinoma," BMC Surgery, vol. 13, article 12, 2013.

[4] H. Oettle, S. Post, P. Neuhaus et al., "Adjuvant chemotherapy with gemcitabine vs observation in patients undergoing curative-intent resection of pancreatic cancer: a randomized controlled trial," The Journal of the American Medical Association, vol. 297, no. 3, pp. 267-277, 2007.

[5] J. P. Neoptolemos, D. D. Stocken, C. Tudur Smith et al., "Adjuvant 5-fluorouracil and folinic acid vs observation for pancreatic cancer: composite data from the ESPAC-1 and -3(v1) trials," British Journal of Cancer, vol. 100, no. 2, pp. 246-250, 2009.

[6] J.-B. M. Koorstra, G. Feldmann, N. Habbe, and A. Maitra, "Morphogenesis of pancreatic cancer: role of pancreatic intraepithelial neoplasia (PanINs)," Langenbeck's Archives of Surgery, vol. 393, no. 4, pp. 561-570, 2008.

[7] D. J. Brat, K. D. Lillemoe, C. J. Yeo, P. B. Warfield, and R. H. Hruban, "Progression of pancreatic intraductal neoplasias to infiltrating adenocarcinoma of the pancreas," American Journal of Surgical Pathology, vol. 22, no. 2, pp. 163-169, 1998.

[8] A. L. Cubilla and P. J. Fitzgerald, "Morphological lesions associated with human primary invasive nonendocrine pancreas cancer," Cancer Research, vol. 36, no. 7, pp. 2690-2698, 1976.

[9] A. Andea, F. Sarkar, and V. N. Adsay, "Clinicopathological correlates of pancreatic intraepithelial neoplasia: a comparative analysis of 82 cases with and 152 cases without pancreatic ductal adenocarcinoma," Modern Pathology, vol. 16, no. 10, pp. 9961006, 2003.

[10] K. Brune, T. Abe, M. Canto et al., "Multifocal neoplastic precursor lesions associated with lobular atrophy of the pancreas in patients having a strong family history of pancreatic cancer," American Journal of Surgical Pathology, vol. 30, no. 9, pp. 10671076, 2006.

[11] C. Shi, A. P. Klein, M. Goggins et al., "Increased prevalence of precursor lesions in familial pancreatic cancer patients," Clinical Cancer Research, vol. 15, no. 24, pp. 7737-7743, 2009.

[12] H. Matthaei, R. D. Schulick, R. H. Hruban, and A. Maitra, "Cystic precursors to invasive pancreatic cancer," Nature Reviews Gastroenterology and Hepatology, vol. 8, no. 3, pp. 141-150, 2011.

[13] H. Uehara, A. Nakaizumi, O. Ishikawa et al., "Development of ductal carcinoma of the pancreas during follow-up of branch duct intraductal papillary mucinous neoplasm of the pancreas," Gut, vol. 57, no. 11, pp. 1561-1565, 2008.

[14] M. Distler, S. Kersting, M. Niedergethmann et al., "Pathohistological subtype predicts survival in patients with intraductal papillary mucinous neoplasm (IPMN) of the pancreas," Annals of Surgery, vol. 258, no. 2, pp. 324-330, 2013.

[15] G. Zamboni, K. Hirabayashi, P. Castelli, and A. M. Lennon, "Precancerous lesions of the pancreas," Best Practice \& Research. Clinical Gastroenterology, vol. 27, no. 2, pp. 299-322, 2013.

[16] R. H. Hruban, N. V. Adsay, J. Albores-Saavedra et al., "Pancreatic intraepithelial neoplasia: a new nomenclature and classification system for pancreatic duct lesions," American Journal of Surgical Pathology, vol. 25, no. 5, pp. 579-586, 2001.

[17] R. H. Hruban, K. Takaori, D. S. Klimstra et al., "An illustrated consensus on the classification of pancreatic intraepithelial neoplasia and intraductal papillary mucinous neoplasms," American Journal of Surgical Pathology, vol. 28, no. 8, pp. 977-987, 2004.

[18] A. Maitra, N. V. Adsay, P. Argani et al., "Multicomponent analysis of the pancreatic adenocarcinoma progression model using a pancreatic intraepithelial neoplasia tissue microarray," Modern Pathology, vol. 16, no. 9, pp. 902-912, 2003.

[19] J. Lüttges, G. Zamboni, D. Longnecker, and G. Klöppel, “The immunohistochemical mucin expression pattern distinguishes different types of intraductal papillary mucinous neoplasms of the pancreas and determines their relationship to mucinous noncystic carcinoma and ductal adenocarcinoma," American Journal of Surgical Pathology, vol. 25, no. 7, pp. 942-948, 2001.

[20] K. Nagata, M. Horinouchi, M. Saitou et al., "Mucin expression profile in pancreatic cancer and the precursor lesions," Journal of Hepato-Biliary-Pancreatic Surgery, vol. 14, no. 3, pp. 243-254, 2007.

[21] N. V. Adsay, K. Merati, A. Andea et al., "The dichotomy in the preinvasive neoplasia to invasive carcinoma sequence in the pancreas: differential expression of MUC1 and MUC2 supports the existence of two separate pathways of carcinogenesis," Modern Pathology, vol. 15, no. 10, pp. 1087-1095, 2002.

[22] G. E. Kim, H. I. Bae, H. U. Park et al., "Aberrant expression of MUC5AC and MUC6 gastric mucins and sialyl Tn antigen 
in intraepithelial neoplasms of the pancreas," Gastroenterology, vol. 123, no. 4, pp. 1052-1060, 2002.

[23] S. Yonezawa, M. Higashi, N. Yamada, and M. Goto, "Precursor lesions of pancreatic cancer," Gut, vol. 2, no. 3, pp. 137-154, 2008.

[24] H.-U. Park, J.-W. Kim, G. E. Kim et al., "Aberrant expression of MUC3 and MUC4 membrane-associated mucins and sialyl $\mathrm{Le}(\mathrm{x})$ antigen in pancreatic intraepithelial neoplasia," Pancreas, vol. 26, no. 3, pp. e48-e54, 2003.

[25] M. J. Swartz, S. K. Batra, G. C. Varshney et al., "MUC4 expression increases progressively in pancreatic intraepithelial neoplasia," American Journal of Clinical Pathology, vol. 117, no. 5, pp. 791-796, 2002.

[26] M. Löhr, G. Klöppel, P. Maisonneuve, A. B. Lowenfels, and J. Lüttges, "Frequency of K-ras mutations in pancreatic intraductal neoplasias associated with pancreatic ductal adenocarcinoma and chronic pancreatitis: a meta-analysis," Neoplasia, vol. 7, no. 1, pp. 17-23, 2005.

[27] R. H. Hruban, A. D. M. van Mansfeld, G. J. A. Offerhaus et al., "K-ras oncogene activation in adenocarcinoma of the human pancreas: a study of 82 carcinomas using a combination of mutant-enriched polymerase chain reaction analysis and allele-specific oligonucleotide hybridization," American Journal of Pathology, vol. 143, no. 2, pp. 545-554, 1993.

[28] C. Almoguera, D. Shibata, K. Forrester, J. Martin, N. Arnheim, and M. Perucho, "Most human carcinomas of the exocrine pancreas contain mutant c-K-ras genes," Cell, vol. 53, no. 4, pp. 549-554, 1988.

[29] S. R. Hingorani, E. F. Petricoin III, A. Maitra et al., "Preinvasive and invasive ductal pancreatic cancer and its early detection in the mouse," Cancer Cell, vol. 4, no. 6, pp. 437-450, 2003.

[30] A. Maitra, S. E. Kern, and R. H. Hruban, "Molecular pathogenesis of pancreatic cancer," Best Practice \& Research. Clinical Gastroenterology, vol. 20, no. 2, pp. 211-226, 2006.

[31] C. Caldas, S. A. Hahn, L. T. da Costa et al., "Frequent somatic mutations and homozygous deletions of the p16 (MTS1) gene in pancreatic adenocarcinoma," Nature Genetics, vol. 8, no. 1, pp. 27-32, 1994.

[32] S. E. Kern, "p53: tumor suppression through control of the cell cycle," Gastroenterology, vol. 106, no. 6, pp. 1708-1711, 1994.

[33] J. Massagué, S. W. Blain, and R. S. Lo, "TGFbeta signaling in growth control, cancer, and heritable disorders," Cell, vol. 103, no. 2, pp. 295-309, 2000.

[34] M. Schutte, R. H. Hruban, L. Hedrick et al., "DPC4 gene in various tumor types," Cancer Research, vol. 56, no. 11, pp. 25272530, 1996.

[35] S. J. Clark, "Action at a distance: epigenetic silencing of large chromosomal regions in carcinogenesis," Human Molecular Genetics, vol. 16, no. 1, pp. R88-R95, 2007.

[36] A. C. Tan, A. Jimeno, S. H. Lin et al., "Characterizing DNA methylation patterns in pancreatic cancer genome," Molecular Oncology, vol. 3, no. 5-6, pp. 425-438, 2009.

[37] M. G. House, J. G. Herman, M. Z. Guo et al., "Aberrant hypermethylation of tumor suppressor genes in pancreatic endocrine neoplasms," Annals of Surgery, vol. 238, no. 3, pp. 423-432, 2003

[38] N. Sato, N. Fukushima, R. H. Hruban, and M. Goggins, "CpG island methylation profile of pancreatic intraepithelial neoplasia," Modern Pathology, vol. 21, no. 3, pp. 238-244, 2008.

[39] M. Goggins, "Identifying molecular markers for the early detection of pancreatic neoplasia," Seminars in Oncology, vol. 34, no. 4, pp. 303-310, 2007.
[40] H. Matthaei, S.-M. Hong, S. C. Mayo et al., "Presence of pancreatic intraepithelial neoplasia in the pancreatic transection margin does not influence outcome in patients with R0 resected pancreatic cancer," Annals of Surgical Oncology, vol. 18, no. 12, pp. 3493-3499, 2011.

[41] M. Kosmahl, U. Pauser, K. Peters et al., "Cystic neoplasms of the pancreas and tumor-like lesions with cystic features: a review of 418 cases and a classification proposal," Virchows Archiv, vol. 445, no. 2, pp. 168-178, 2004.

[42] R. Grützmann and H. D. Saeger, "Cystic tumors of the pancreas," Chirurg, vol. 81, no. 8, pp. 755-769, 2010.

[43] W. R. Brugge, G. Y. Lauwers, D. Sahani, C. Fernandez-Del Castillo, and A. L. Warshaw, "Cystic neoplasms of the pancreas," The New England Journal of Medicine, vol. 351, no. 12, pp. 12181226, 2004

[44] G. Klöppel, E. Solcia, D. S. Longnecker et al., Histological Typing of Tumours of the Exocrine Pancreas: World Health Organization International Histological Classification of Tumours, Springer, New York, NY, USA, 2nd edition, 1998.

[45] N. V. Adsay, K. Merati, O. Basturk et al., "Pathologically and biologically distinct types of epithelium in intraductal papillary mucinous neoplasms: delineation of an "intestinal" pathway of carcinogenesis in the pancreas," American Journal of Surgical Pathology, vol. 28, no. 7, pp. 839-848, 2004.

[46] N. V. Adsay, K. Merati, H. Nassar et al., "Pathogenesis of colloid (pure mucinous) carcinoma of exocrine organs: coupling of gelforming mucin (MUC2) production with altered cell polarity and abnormal cell-stroma interaction may be the key factor in the morphogenesis and indolent behavior of colloid carcinoma in the breast and pancreas," American Journal of Surgical Pathology, vol. 27, no. 5, pp. 571-578, 2003.

[47] R. Grützmann, M. Niedergethmann, C. Pilarsky, G. Klöppel, and H. D. Saeger, "Intraductal papillary mucinous tumors of the pancreas: biology, diagnosis, and treatment," Oncologist, vol. 15, no. 12, pp. 1294-1309, 2010.

[48] T. Furukawa, T. Hatori, I. Fujita et al., "Prognostic relevance of morphological types of intraductal papillary mucinous neoplasms of the pancreas," Gut, vol. 60, no. 4, pp. 509-516, 2011.

[49] O. Basturk, S. Khayyata, D. S. Klimstra et al., "Preferential expression of MUC6 in oncocytic and pancreatobiliary types of intraductal papillary neoplasms highlights a pyloropancreatic pathway, distinct from the intestinal pathway, in pancreatic carcinogenesis," American Journal of Surgical Pathology, vol. 34, no. 3, pp. 364-370, 2010.

[50] M. Tanaka, C. F.-D. Castillo, V. Adsay et al., "International consensus guidelines 2012 for the management of IPMN and MCN of the pancreas," Pancreatology, vol. 12, pp. 183-197, 2012.

[51] K. Nagai, R. Doi, A. Kida et al., "Intraductal papillary mucinous neoplasms of the pancreas: clinicopathologic characteristics and long-term follow-up after resection," World Journal of Surgery, vol. 32, no. 2, pp. 271-280, 2008.

[52] R. Grützmann, S. Post, H. D. Saeger, and M. Niedergethmann, "Intraductal Papillary Mucinous Neoplasia (IPMN) of the pancreas: its diagnosis, treatment, and prognosis," Deutsches Ärzteblatt International, vol. 108, no. 46, pp. 788-794, 2011.

[53] R. Salvia, S. Partelli, S. Crippa et al., "Intraductal papillary mucinous neoplasms of the pancreas with multifocal involvement of branch ducts," American Journal of Surgery, vol. 198, no. 5, pp. 709-714, 2009. 
[54] S. T. Chari, D. Yadav, T. C. Smyrk et al., "Study of recurrence after surgical resection of intraductal papillary mucinous neoplasm of the pancreas," Gastroenterology, vol. 123, no. 5, pp. 1500-1507, 2002.

[55] F. T. Bosman, F. Carneiro, R. H. Hruban, and N. Theise, Classification of Tumours of the Digestive System, WHO, Lyon, France, 2010.

[56] M. Niedergethmann, R. Grützmann, R. Hildenbrand et al., "Outcome of invasive and noninvasive intraductal papillarymucinous neoplasms of the pancreas (IPMN): a 10-year experience," World Journal of Surgery, vol. 32, no. 10, pp. 2253-2260, 2008.

[57] T. Furukawa, G. Klöppel, N. Volkan Adsay et al., "Classification of types of intraductal papillary-mucinous neoplasm of the pancreas: a consensus study," Virchows Archiv, vol. 447, no. 5, pp. 794-799, 2005.

[58] S. Yonezawa, M. Horinouchi, M. Osako et al., "Gene expression of gastric type mucin (MUC5AC) in pancreatic tumors: its relationship with the biological behavior of the tumor," Pathology International, vol. 49, no. 1, pp. 45-54, 1999.

[59] I. Kitazono, M. Higashi, S. Kitamoto et al., "Expression of MUC4 mucin is observed mainly in the intestinal type of intraductal papillary mucinous neoplasm of the pancreas," Pancreas, vol. 42, no. 7, pp. 1120-1128, 2013.

[60] M. Distler, T. Welsch, D. Aust, J. Weitz, and R. Grützmann, "Intraductal papillary mucinous neoplasm of the pancreas (IPMN) - standards and new aspects," Zentralbl Chir. In press.

[61] H. Yamaguchi, Y. Kuboki, T. Hatori et al., "The discrete nature and distinguishing molecular features of pancreatic intraductal tubulopapillary neoplasms and intraductal papillary mucinous neoplasms of the gastric type, pyloric gland variant," The Journal of Pathology, vol. 231, no. 3, pp. 335-341, 2013.

[62] Y. Sadakari, K. Ohuchida, K. Nakata et al., "Invasive carcinoma derived from the nonintestinal type intraductal papillary mucinous neoplasm of the pancreas has a poorer prognosis than that derived from the intestinal type," Surgery, vol. 147, no. 6, pp. 812$817,2010$.

[63] G. A. Poultsides, S. Reddy, J. L. Cameron et al., "Histopathologic basis for the favorable survival after resection of intraductal papillary mucinous neoplasm-associated invasive adenocarcinoma of the pancreas," Annals of Surgery, vol. 251, no. 3, pp. 470-476, 2010.

[64] M. Mino-Kenudson, C. Fernández-del Castillo, Y. Baba et al., "Prognosis of invasive intraductal papillary mucinous neoplasm depends on histological and precursor epithelial subtypes," Gut, vol. 60, no. 12, pp. 1712-1720, 2011.

[65] Y. Murakami, K. Uemura, T. Sudo et al., "Postoperative adjuvant chemotherapy improves survival after surgical resection for pancreatic carcinoma," Journal of Gastrointestinal Surgery, vol. 12, no. 3, pp. 534-541, 2008.

[66] J. Kim, K. T. Jang, S. Mo Park et al., "Prognostic relevance of pathologic subtypes and minimal invasion in intraductal papillary mucinous neoplasms of the pancreas," Tumour Biology, vol. 32, no. 3, pp. 535-542, 2011.

[67] S. Fritz, C. Fernandez-del Castillo, M. Mino-Kenudson et al., "Global genomic analysis of intraductal papillary mucinous neoplasms of the pancreas reveals significant molecular differences compared to ductal adenocarcinoma," Annals of Surgery, vol. 249, no. 3, pp. 440-447, 2009.
[68] F. Schönleben, W. Qiu, K. C. Bruckman et al., "BRAF and KRAS gene mutations in intraductal papillary mucinous neoplasm/carcinoma (IPMN/IPMC) of the pancreas," Cancer Letters, vol. 249, no. 2, pp. 242-248, 2007.

[69] D. Mohri, Y. Asaoka, H. Ijichi et al., "Different subtypes of intraductal papillary mucinous neoplasm in the pancreas have distinct pathways to pancreatic cancer progression," Journal of Gastroenterology, vol. 47, no. 2, pp. 203-213, 2012.

[70] J. Wu, H. Matthaei, A. Maitra et al., "Recurrent GNAS mutations define an unexpected pathway for pancreatic cyst development," Science Translational Medicine, vol. 3, no. 92, article 92ra66, 2011.

[71] T. Furukawa, Y. Kuboki, E. Tanji et al., "Whole-exome sequencing uncovers frequent GNAS mutations in intraductal papillary mucinous neoplasms of the pancreas," Scientific Reports, vol. 1, article 161, 2011.

[72] M. Dal Molin, H. Matthaei, J. Wu et al., "Clinicopathological correlates of activating GNAS mutations in intraductal papillary mucinous neoplasm (IPMN) of the pancreas," Annals of Surgical Oncology, vol. 20, no. 12, pp. 3802-3808, 2013.

[73] H. D. Xiao, H. Yamaguchi, D. Dias-Santagata et al., "Molecular characteristics and biological behaviours of the oncocytic and pancreatobiliary subtypes of intraductal papillary mucinous neoplasms," Journal of Pathology, vol. 224, no. 4, pp. 508-516, 2011.

[74] A. A. Siddiqui, T. E. Kowalski, R. Kedika et al., "EUS-guided pancreatic fluid aspiration for DNA analysis of KRAS and GNAS mutations for the evaluation of pancreatic cystic neoplasia: a pilot study," Gastrointestinal Endoscopy, vol. 77, no. 4, pp. 669-670, 2013.

[75] M. Kanda, S. Knight, M. Topazian et al., "Mutant GNAS detected in duodenal collections of secretin-stimulated pancreatic juice indicates the presence or emergence of pancreatic cysts," Gut, vol. 62, no. 7, pp. 1024-1033, 2013.

[76] M. Kanda, Y. Sadakari, M. Borges et al., "Mutant TP53 in duodenal samples of pancreatic juice from patients with pancreatic cancer or high-grade dysplasia," Clinical Gastroenterology and Hepatology, vol. 11, no. 6, pp. 719.e5-730.e5, 2013.

[77] K. K. Das, H. Xiao, X. Geng et al., "mAb Das-1 is specific for high-risk and malignant intraductal papillary mucinous neoplasm (IPMN)," Gut, 2013.

[78] S. M. Hong, N. Omura, A. Vincent et al., "Genome-wide CpG island profiling of intraductal papillary mucinous neoplasms of the pancreas," Clinical Cancer Research, vol. 18, no. 3, pp. 700$712,2012$.

[79] T. Hara, D. Ikebe, A. Odaka et al., "Preoperative histological subtype classification of intraductal papillary mucinous neoplasms (IPMN) by pancreatic juice cytology with MUC stain," Annals of Surgery, vol. 257, no. 6, pp. 1103-1111, 2013.

[80] M. B. Pitman, B. A. Centeno, E. S. Daglilar, W. R. Brugge, and M. Mino-Kenudson, "Cytological criteria of high-grade epithelial atypia in the cyst fluid of pancreatic intraductal papillary mucinous neoplasms," Cancer Cytopathology, vol. 122, no. 1, pp. 40-47, 2014.

[81] A. V. Maker, N. Katabi, M. Gonen et al., "Pancreatic cyst fluid and serum mucin levels predict dysplasia in intraductal papillary mucinous neoplasms of the pancreas," Annals of Surgical Oncology, vol. 18, no. 1, pp. 199-206, 2011.

[82] A. V. Maker, N. Katabi, L.-X. Qin et al., "Cyst fluid interleukin$1 \beta$ (IL1 $\beta$ ) levels predict the risk of carcinoma in intraductal papillary mucinous neoplasms of the pancreas," Clinical Cancer Research, vol. 17, no. 6, pp. 1502-1508, 2011. 
[83] M. B. Pitman, P. J. Michaels, V. Deshpande, W. R. Brugge, and B. C. Bounds, "Cytological and cyst fluid analysis of small $(\leq 3 \mathrm{~cm})$ branch duct intraductal papillary mucinous neoplasms adds value to patient management decisions," Pancreatology, vol. 8, no. 3, pp. 277-284, 2008.

[84] N. P. Valsangkar, V. Morales-Oyarvide, S. P. Thayer et al., "851 resected cystic tumors of the pancreas: a 33-year experience at the Massachusetts General Hospital," Surgery, vol. 152, no. 3, supplement 1, pp. S4-S12, 2012.

[85] K. Yamao, A. Yanagisawa, K. Takahashi et al., "Clinicopathological features and prognosis of mucinous cystic neoplasm with ovarian-type stroma: a multi-institutional study of the Japan pancreas society," Pancreas, vol. 40, no. 1, pp. 67-71, 2011.

[86] S. Crippa, R. Salvia, A. L. Warshaw et al., "Mucinous cystic neoplasm of the pancreas is not an aggressive entity: lessons from 163 resected patients," Annals of Surgery, vol. 247, no. 4, pp. 571-579, 2008.

[87] S. Cizginer, B. Turner, A. R. Bilge, C. Karaca, M. B. Pitman, and W. R. Brugge, "Cyst fluid carcinoembryonic antigen is an accurate diagnostic marker of pancreatic mucinous cysts," Pancreas, vol. 40, no. 7, pp. 1024-1028, 2011, Erratum in "Cyst fluid carcinoembryonic antigen is an accurate diagnostic marker of pancreatic mucinous cysts", Pancreas, vol. 42, no. 4, pp. 728, 2013.

[88] W. G.-U. Park, R. Mascarenhas, M. Palaez-Luna et al., "Diagnostic performance of cyst fluid carcinoembryonic antigen and amylase in histologically confirmed pancreatic cysts," Pancreas, vol. 40, no. 1, pp. 42-45, 2011.

[89] G. Zamboni, A. Scarpa, G. Bogina et al., "Mucinous cystic tumors of the pancreas: clinicopathological features, prognosis, and relationship to other mucinous cystic tumors," American Journal of Surgical Pathology, vol. 23, no. 4, pp. 410-422, 1999.

[90] M. L. Baker, E. S. Seeley, R. Pai et al., "Invasive mucinous cystic neoplasms of the pancreas," Experimental and Molecular Pathology, vol. 93, no. 3, pp. 345-349, 2012.

[91] R. E. Jimenez, A. L. Warshaw, K. Z'graggen et al., "Sequential accumulation of K-ras mutations and p53 overexpression in the progression of pancreatic mucinous cystic neoplasms to malignancy," Annals of Surgery, vol. 230, no. 4, pp. 501-511, 1999.

[92] C. A. Iacobuzio-Donahue, R. E. Wilentz, P. Argani et al., "Dpc4 protein in mucinous cystic neoplasms of the pancreas: frequent loss of expression in invasive carcinomas suggests a role in genetic progression," American Journal of Surgical Pathology, vol. 24, no. 11, pp. 1544-1548, 2000.

[93] J. Wu, Y. Jiao, M. Dal Molin et al., "Whole-exome sequencing of neoplastic cysts of the pancreas reveals recurrent mutations in components of ubiquitin-dependent pathways," Proceedings of the National Academy of Sciences of the United States of America, vol. 108, no. 52, pp. 21188-21193, 2011. 


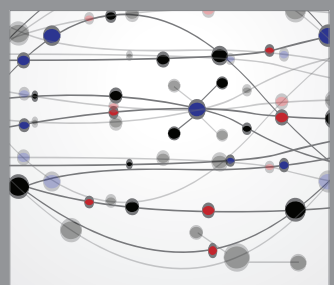

The Scientific World Journal
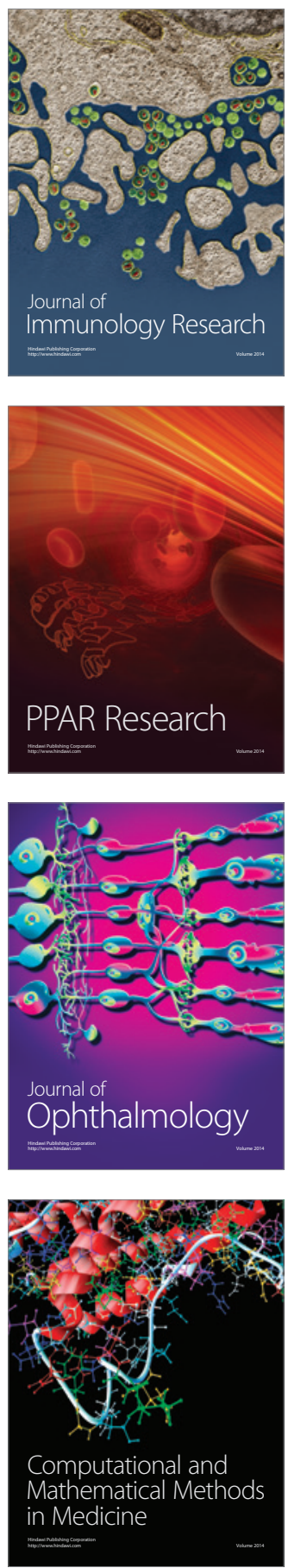

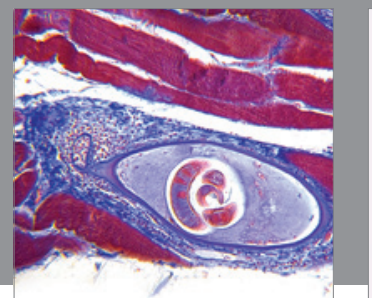

Gastroenterology

Research and Practice
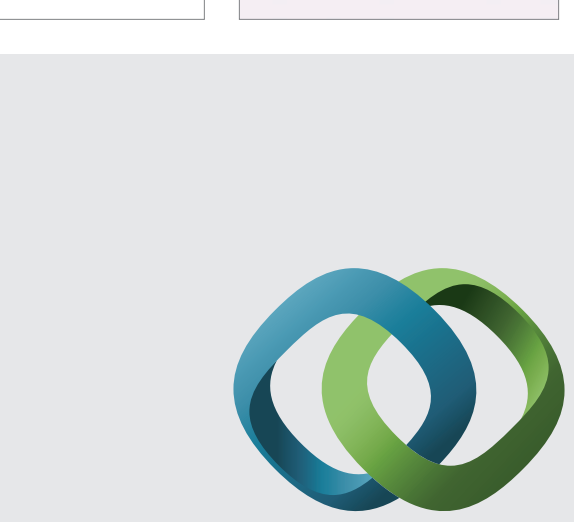

\section{Hindawi}

Submit your manuscripts at

http://www.hindawi.com
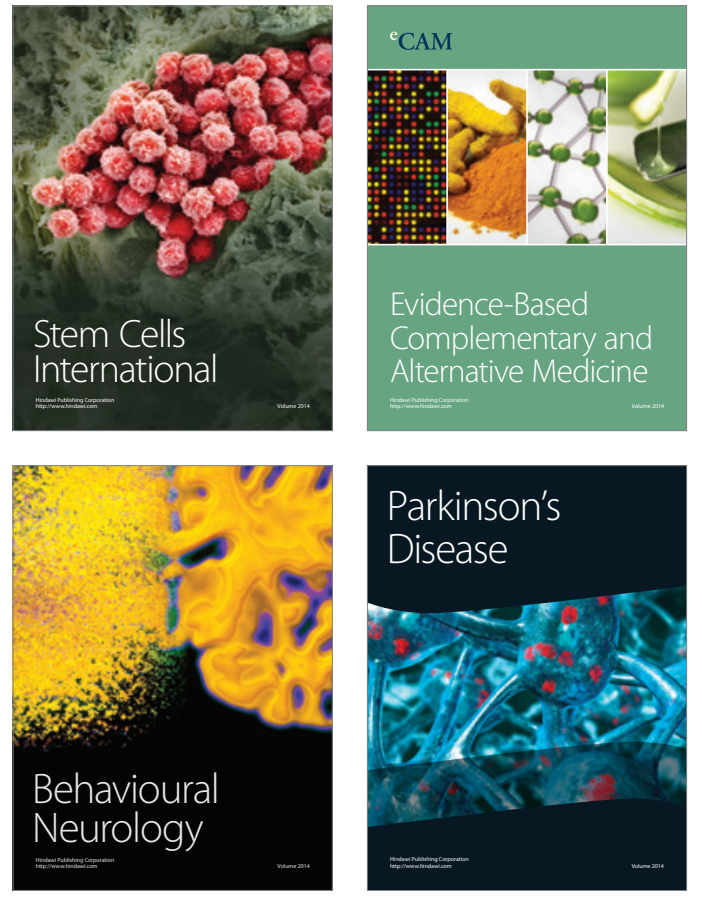
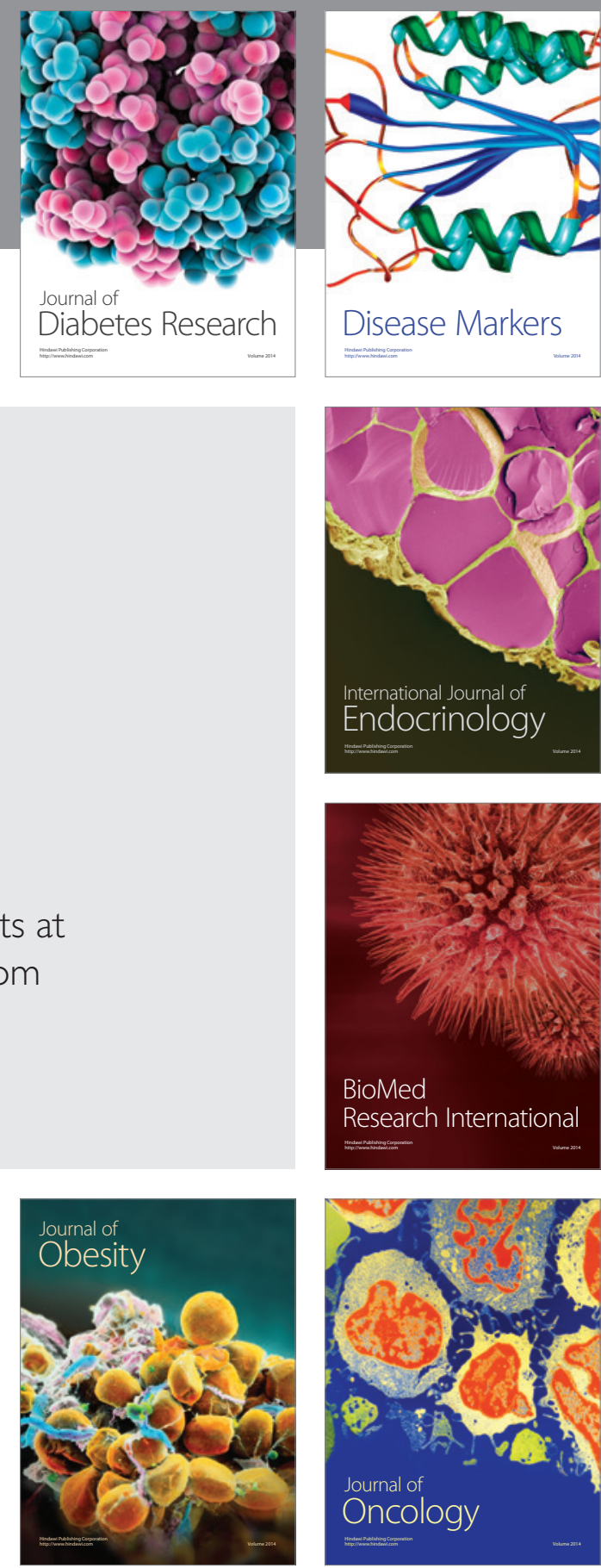

Disease Markers
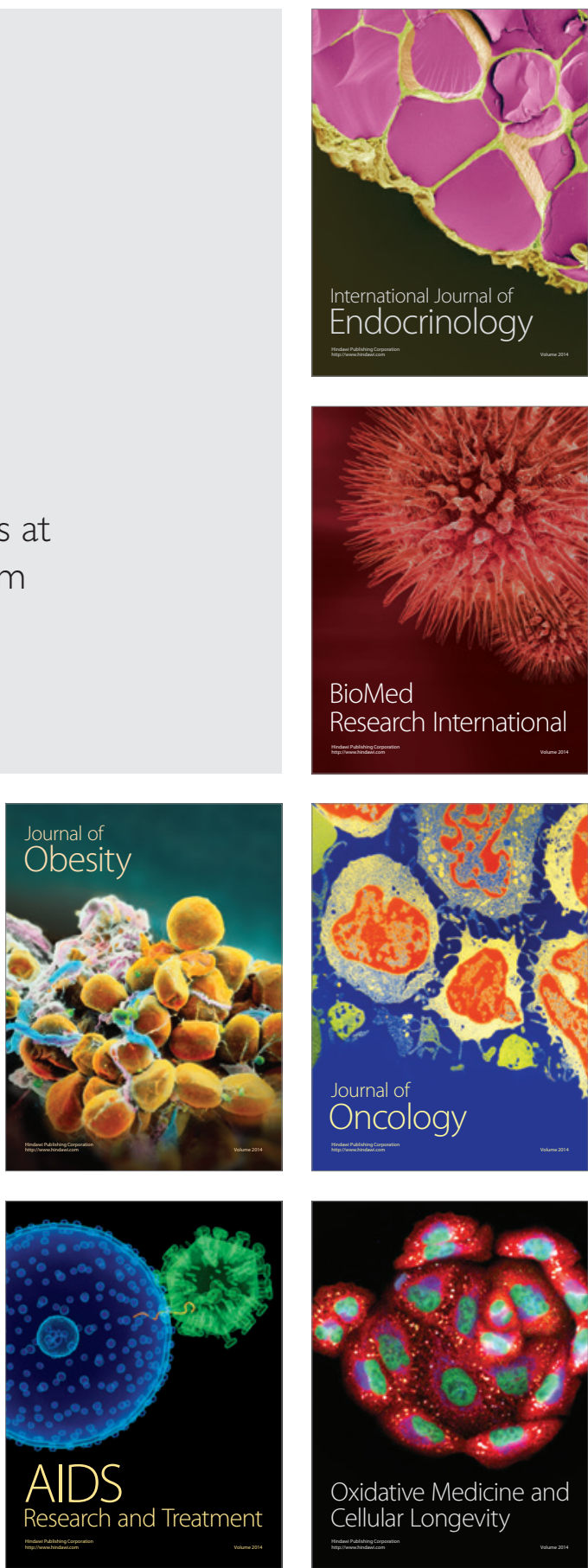